\title{
PENGEMBANGAN BUKU AJAR KIMIA BERBASIS KEIMANAN UNTUK MA DAN SMA-IT
}

\author{
Herdika Thio Firmansyah ${ }^{1 *}$, Elfi Susanti $\mathrm{VH}^{2}$, Sulistyo Saputro ${ }^{2}$ \\ Program Studi Pendidikan Kimia, FKIP, Universitas Sebelas Maret, Surakarta, Indonesia \\ *Keperluan korespondensi: Tel/Fax 081380980559, e-mail: firmansyaheducator@gmail.com
}

\begin{abstract}
ABSTRAK
Tujuan penelitian ini adalah (1) mengembangkan buku ajar kimia berbasis keimanan untuk MA dan SMA-IT serta (2) mengetahui kelayakan buku ajar kimia berbasis keimanan untuk MA dan SMA-IT. Dalam penelitian ini dikembangkan buku ajar berbasis keimanan mengikuti langkah Borg dan Gall (1983) serta mengadaptasi nilai keimanan dari Zarman (2012) yaitu (1) menyebutkan asma Allah ke dalam kalimat yang dianggap tidak mengkui eksistensi-Nya dalam penciptaan atau pengaturan objek di materi kimia, (2) menghubungkan temuan ilmiah dalam kimia dengan ayat Alquran dan Hadis yang terkait, (3) mencantumkan amalan yang terkait dengan materi setelah mempelajarinya (4) mencantumkan ilmuwan muslim yang berpengaruh di bidang kimia, dan (5) mencantumkan adab-adab dalam menuntut ilmu kimia. Hasil dari penelitian ini yaitu buku ajar kimia berbasis keimanan yang telah dikembangkan layak dengan digunakan dalam proses pembelajaran kimhad di MA maupun SMA-IT dengan predikat bagus.
\end{abstract}

Kata kunci: Pengembangan, Buku Ajar Kimia, Keimanan

\section{PENDAHULUAN}

Tujuan Pendidikan Nasional Indonesia sebagaimana termaktub dalam UU No 20 Tahun 2003 adalah mengembangkan kemampuan dan membentuk watak serta peradaban bangsa yang bermartabat dalam rangka mencerdaskan kehidupan bangsa, bertujuan untuk berkembangnya potensi siswa agar menjadi manusia yang beriman dan bertakwa kepada Tuhan Yang Maha Esa, berakhlak mulia, sehat, berilmu, cakap, kreatif, mandiri, dan menjadi warga Negara yang demokratis serta bertanggung jawab. Pendidikan nasional Indonesia tidak hanya bertujuan menjadikan manusia yang cakap dalam ilmu pengetahuan dan sosial, namun juga manusia yang religius. Karena tujuan pendidikan tersebut sangat mulia, maka dari itu pemerintah seharusnya menyiapkan kurikulum hingga perangkat pembelajaran yang dapat mewujudkan tujuan pendidikan nasional tersebut.

Salah satu elemen perangkat pembelajaran adalah buku ajar. Buku ajar merupakan alat bantu pengajaran utama di dalam kelas, artinya sebagai sumber pengetahuan bagi siswa [1] dan memfasilitasi guru dalam memilih topik pelajaran [2]. Segala informasi seperti materi hingga ideologi penulis [3] sebagai bentuk interpretasinya terhadap kurikulum [2] dapat ditemukan dalamnya. Selain sebagai alat, buku pelajaran adalah refleksi dari kurikulum yang berlaku [4].

Kurikulum yang berlaku di Indonesia adalah Kurikulum 2013. Kurikulum 2013 memiliki tujuan yaitu mempersiapkan manusia Indonesia agar memiliki kemampuan hidup sebagai pribadi dan warga negara yang beriman. Tujuan kurikulum di atas memiliki konsekuensi, yaitu pada mata pelajaran harus memiliki kompetensi inti sikap spiritual yaitu beriman. Bukan hanya mata pelajaran agama, namun semua mata pelajaran tidak terkecuali mata pelajaran kimia.

Kimia merupakan cabang ilmu sains yang mempelajari tentang materi, sifat dan perilaku [5], eksperimental dan berasal dari laboratorium [6]. Pengertian tersebut menandakan Kimia merupakan 
ilmu yang menggunakan pendekatan saintifik artinya segala aktivitasnya dilakukan menggunakan pengamatan, percobaan, pengukuran, perumusan, pengujian, dan perubahan hipotesis. Pendekatan saintifik cenderung menolak wahyu sebagai sumber informasi yang absolut, sehingga kontradiktif dengan epistemologi Islam. Pengetahuan adalah konsep spiritual yang tidak terlepas dari Allah [7]. Artinya penerimaan wahyu sebagai sumber ilmu disertai keimanan kepada Allah dan memengaruhi cara pandang seorang muslim terhadap benda-benda ciptaan dan penciptanya [8]. Nilai-nilai keimanan kepada Allah semestinya diimplementasikan dalam buku ajar.

Buku ajar kimia yang digunakan oleh siswa MA dan SMA-IT di Surakarta belum bermuatan nilai keimanan. Maka untuk menjawab permasalahan tersebut dilakukan pengembangan buku ajar kimia yang berbasis keimanan.

\section{METODE PENELITIAN}

Metode dalam penelitian ini yaitu Research and Development (R\&D) mengikuti langkah Borg dan Gall [9]. Adapun langkah-langkahnya sebagai berikut: (1) Studi pendahuluan atau analisis kebutuhan, (2) Pengembangan, (3) Desk Evaluation, (4) Revisi produk, (5) Ujicoba produk, dan (6) Revisi produk tahap akhir.

Subjek ujicoba dalam penelitian ini adalah dosen ahli materi, ahli penyajian, dan ahli integrasi keimanan, guru, dan siswa di MAN 1 Surakarta, MA AI Islam Jamsaren, dan SMA-IT Nur Hidayah. Masing-masing sekolah sebanyak 2 guru dan 30 siswa yang diambil menggunakan teknik random sampling.

Jenis data yang diperoleh adalah data kualitatif dan kuantitatif, dimana data kualitatif diperoleh dari saran dan evaluasi dosen ahli dan guru sedangkan data kuantitatif adalah hasil respon angket dosen ahli, guru, dan siswa yang telah disediakan.

Hasil skor angket diolah dan dianalisis, lalu ditentukan kelayakannya menurut kriteria dari Pusat Kurikulum dan Perbukuan, disajikan pada Tabel 1.
Tabel 1. Hasil kelayakan skor kelayakan

\begin{tabular}{cl}
\hline Presentase & \multicolumn{1}{c}{ Kriteria } \\
\hline $85 \% \leq \mathrm{Ps} \leq 100 \%$ & Layak(Sangat Bagus) \\
$61 \% \leq \mathrm{Ps} \leq 80 \%$ & Layak (Bagus) \\
$41 \% \leq \mathrm{Ps} \leq 60 \%$ & Layak (Cukup) \\
$0 \% \leq \mathrm{Ps} \leq 40 \%$ & Tidak layak \\
\hline${ }^{*} \mathrm{Ps}=$ Presentase sub variabel
\end{tabular}

\section{HASIL DAN PEMBAHASAN}

\section{Hasil Studi Pendahulan}

Pada langkah ini dilakukan analisis terhadap pembelajaran kimia dan bahan ajarnya yang digunakan di 3 sekolah yaitu MAN 1 Surakarta, MA Al Islam Jamsaren, dan SMA-IT Nur Hidayah. Analisis buku ajar berupa analisis nilai keimanan yang terkandung dalam buku tersebut. Tahap analisis tersebut diperoleh hasil bahwa pembelajaran kimia di tiga sekolah tersebut siswa merasa kebingungan dalam belajar kimia lalu guru menggunakan stimulus berupa mengaitkan materi kimia dengan ayatayat Alquran. Pendekatan tersebut ternyata cukup efektif untuk memotivasi siswa memahami materi kimia yang disampaikan.

Bahan ajar yang digunakan dalam pembelajaran adalah buku ajar karena mudah didapatkan di toko buku atau perpustakaan sekolah. Selain itu muatan materi dalam buku ajar luas dan contoh soal bervariasi. Buku ajar yang digunakan adalah buku ajar A oleh MA Al Islam Jamsaren, dan buku ajar $C$ oleh MAN 1 Surakarta dan SMA-IT Nur Hidayah. Setelah itu dianalisis karakteristik nilai-nilai keimanan dalam buku ajar di atas menggunakan indikator (1) pengantar berisi nasihat islami, (2) ungkapan kemahakuasaan Allah, (3) ungkapan hikmah dari penciptaan ilmu kimia, (4) koreksi konsep kimia modern yang bertentangan dengan pandangan hidup Islam, (5) pencantuman ayat Alquran dan Hadis relevan terkait topik, (6) informasi kiprah ilmuwan Muslim dalam bidang kimia, dan (7) pengaitan materi kimia dengan penerapan ajaran Islam [10], hasilnya adalah buku ajar A ini secara keseluruhan menyajikan judul bab, judul pembelajaran, karakter yang dikembangkan, kata kunci, laman kimia, 
contoh soal, rangkuman, dan latihan soal. Pada bab 2 materi struktur atom dan sistem periodik unsur, isi bab dimulai dari pendahuluan dipaparkan apakah zat yang menyusun suatu materi dan bagaimana pengelompokkan zat-zat tersebut. Inti dari materi memaparkan teori atom para ahli, struktur atom, model atom, dan perkembangan struktur periodik unsur. Tidak ada pengaitan materi dengan Alquran, perenungan terhadap kemahakuasaan Allah, dan eksisteni Allah dalam mengatur struktur atom. Dapat disimpulkan bahwa buku ajar A secara keseluruhan belum mengembangkan karakter menyadari keteraturan dan kompleksitas elektron dalam atom sebagai wujud kebesaran Tuhan Yang Maha Esa dengan kata lain keimanan.

Nilai keimanan pada buku ajar C hanya terdapat tiga indikator keimanan yaitu ungkapan kemahakuasaan Allah, ungkapan hikmah dari penciptaan ilmu kimi, dan pengaitan materi kimia dengan penerapan ajaran Islam. Ungakapan kemahakuasaan Allah tertuang dalam kolom "Coba Renungkan!" sebagai aspek religius.

Kolom tersebut dalam bab I pada halaman 9, bab II halaman 42;60, bab III halaman 103;141;147. Salah satu contoh ungkapan kemahakuasaan Allah pada buku teks kimia $\mathrm{C}$ sebagai berikut. "Coba Anda renungkan. Dalam skala makroskopis, setiap elektron berotasi pada porosnya. Selain berotasi, elektron juga berputar mengelilingi inti (berevolusi). Pada skala makroskopis, pola ini mirip dengan sistem tata surya kita. Planetplanet berotasi sekaligus berevolusi mengelilingi matahari sebagai pusat tata surya. Pada skala lebih besar lagi, sistem tata surya kita juga bergerak mengelilingi pusat galaksi. Jika kita perhatikan, pola keteraturan atom ini terjadi dari skala atom (mikroskopis) yang tidak terlihat sampai skala makroskopis, yaitu alam semesta. Siapa yang mengatur semua ini? Tuhan Yang Mahakuasa-lah yang telah mengatur semua itu sehingga tercipta alam semesta yang demikian indah dan seimbang".

Penulis buku ajar C mengajak siswa bertafakur akan kemahakuasaan Allah dalam mengatur keteraturan atom dalam skala mikroskopis dan makroskopis. Analogi yang digunakan oleh penulis untuk mengungkapkan kemahakuasaan Allah didasarkan teori atom Neils Bohr. Namun letak kolom renungan ini setelah menjelaskan materi bilangan kuantum, sehingga siswa tidak secara langsung dapat memaknai kemahakuasaan Allah di dalam teori atom Bohr.

Ungkapan hikmah dalam buku ajar C dituliskan oleh penulis dalam kolom "Coba Renungkan!". Contohnya pada bab I halaman 9 dan bab III halaman 141. Redaksional yang digunakan penulis sebagai berikut. "Di antara yang menarik dari air adalah proses pembekuannya. Zat-zat cair pada umumnya membeku mulai dari lapisan paling bawah lalu ke lapisan atasnya. Namun, air membeku pada dari arah sebaliknya. Ini adalah sifat anomali (pengecualian) air yang sangat penting bagi keberadaan air di permukaan bumi. Jika air tidak membeku dari atas, dengan kata lain jika es tidak mengapung maka banyak air di wilayah dingin di permukaan bumi yang akan menjadi es. Jika ini yang terjadi maka tidak adakan ada lagi kehidupan di lautan, danau, kolam, dan sungai yang membeku. Oleh karena itu, kita harus bersyukur kepada Tuhan yang telah menciptakan air bersifat demikian". Penulis mengungkapkan hikmah disebalik sifat air sebagai ciptaan Allah.

Pengaitan materi kimia dengan ajaran Islam dalam buku ajar $\mathrm{C}$ dalam kolom "Coba Renungkan!", terdapat pada bab I halaman 9, bab II halaman 42 , bab III halaman 147. Salah satu pengaitan ajaran Islam sebagai berikut. "Teori atom mengalami beberapa kali penyempurnaan. Kenyataan ini menunjukkan bahwa teori yang dibuat oleh manusia masih memiliki kekurangan dan kelemahan. Hanya Tuhanlah Yang Maha benar dan Mahasempurna. Oleh karena itu, kita harus selalu berdoa yang memohon petunjuk dari-Nya. Sudahkah anda melakukannya?". Kalimat tersebut mengindikasikan bahwa penulis mengajak siswa untuk berdoa dan meminta petunjuk kepada Allah karena kekurangan dan kelemahan manusia dalam memahami ilmu kimia. Buku ajar C ini telah representatif untuk digunakan 
pembelajaran di sekolah yang berbasis Islam, namun masih perlu disempurnakan agar mencakup semua aspek keimanan yaitu dengan mengembangkan buku ajar kimia berbasis keimanan

\section{Perencanaan dan Pengembangan Produk}

Pengembangan buku ajar kimia berbasis keimanan ini merupakan prototipe buku pengayaan diperuntukkan siswa kelas X SMA/MA. Karena merupakan prototipe, maka isi buku ajar ini diambil hanya satu bab yaitu bab teori atom, namun pada buku ajar ini dibagi menjadi empat bab sehingga bentuknya seperti buku. Pemilihan materi pada teori atom karena teori atom adalah bagian penting dari pendidikan kimia dan menjadi objek perhatian bagi pendidik kimia [11]. Pembagian bab pada buku yaitu, bab I "Perjalanan Mengungkap Atom", bab II "Ilmuwan Kimia Muslim", bab III "Atom Modern", dan bab IV "Teori Atom Mekanika Kuantum".

Penyusunan buku ajar kimia berbasis keimanan juga hasil adaptasi dari disertasi Wendi Zarman [9]. Adaptasi yang dilakukan adalah indikator nilai keimanan. Nilai keimanan tersebut diambil yang relevan dengan karakteristik mata pelajaran kimia. Dalam pengembangan buku ajar kimia berbasis keimanan ini nilai keimanannya antara lain, (1) menyebutkan asma Allah ke dalam kalimat yang dianggap tidak mengakui eksistensi-Nya dalam penciptaan atau pengaturan objek di materi kimia, (2) menghubungkan temuan ilmiah dalam kimia dengan ayat Alquran dan Hadis yang terkait, (3) mencantumkan amalan yang terkait dengan materi setelah mempelajarinya, (4) mencantumkan ilmuwan Muslim yang berpengaruh di bidang kimia, dan (5) mencantumkan adab-adab dalam menuntut ilmu kimia.

Nilai keimanan tersebut diimplementasikan ke dalam bodytext maupun fitur dalam buku. Implementasi nilai keimanan dalam bodytext yaitu indikator menyebutkan asma Allah ke dalam kalimat yang dianggap tidak mengakui eksistensi-Nya dalam penciptaan atau pengaturan objek di materi kimia. Bentuknya adalah disisipkan kata seperti
"Allah menghendaki"; "Allah mengizinkan"; atau "Allah mengatur". Selain pada bodytext indikator keimanan tersebut juga diimplementasikan ke dalam fitur buku yaitu pada kolom "Keimanan", Indikator lain yang diimplementasikan dalam bodytext adalah menghubungkan temuan ilmiah dalam kimia dengan ayat Alquran dan Hadis yang terkait. Kemudian indikator mencantumkan ilmuwan Muslim yang berpengaruh di bidang kimia pada satu bab utuh yaitu bab II. Untuk indikator lainnya terdapat dalam fitur yang tersaji dalam kolom "Beramal" dan "Beradab".

Selain komponen utama di atas, buku ajar ini dilengkapi peta konsep, kompetensi inti dan kompetensi dasar, apersepsi dalam setiap bab, gambar ilmuwan, ilustrasi gambar yang mendukung materi, contoh soal, latihan soal, rangkuman, dan soal evaluasi. Komponen tersebut adalah komponen pendukung untuk memahami isi buku teks. Mulai dari awal melalui apersepsi dan peta konsep, bagian tengah melalui gambar, latihan soal dan contoh soal, dan pada bagian akhir melalui rangkuman serta soal evaluasi.

\section{Desk Evaluation}

Pada tahap desk evaluation ini produk draf awal atau selanjutnya dinamakan draf I dievaluasi secara kualitatif oleh dosen ahli. Evaluasi dosen ahli berupa saran terkait materi, penyajian, dan integrasi keimanan.

Saran dari dosen ahli materi sebagai berikut:

a. Pada keterangan gambar diusahakan sumbernya bukan dari wikipedia.com.

b. Pada keterangan gambar diusahakan sumbernya bukan dari wikipedia.com.

c. Pada halaman 21 bentuk bola atom (Nitrogen dan Oksigen) disesuaikan dengan ukuran atom.

d. Perhatikan gaya penulisan materi. Bandingkan dengan buku lain apakah terdapat persamaan.

e. Letak ilustrasi gambar dengan materi harus tepat agar tidak membuat bingung siswa. 
f. Penulisan lambang unsur kimia dengan nomor atomnya harus sesuai (subscript atau superscript).

g. Penggambaran diagram orbital pada contoh soal halaman 43 dan 47 belum lengkap.

h. Pengutipan pendapat atau teori dari ilmuwan diusahakan didapat dari sumber primer.

Saran dari dosen ahli penyajian sebagai berikut:

a. Judul "Pendahuluan" diganti prakata penulis

b. Huruf arab untuk sholawat dalam kalimat pembuka di prakata penulis diganti dengan huruf biasa.

c. Kata "Zaman Now" diganti dengan "Zaman Modern" agar sesuai KBBI.

d. Pada awal bab kata "Target Belajar" diganti dengan "Tujuan Belajar".

e. Kalimat "Setelah belajar dan membaca dan bab ini, kami mengharapkan kalian mampu:" kurang efektif.

f. Peta konsep diberikan border pada tiap konsepnya.

g. Penulisan kata "Dzarrah" diganti sesuai KBBI.

h. Huruf pertama pada nama orang wajib capital (ar-Razi diganti Ar-Razi).

i. Perhatikan letak fitur dan bodytext.

j. Perhatikan pemenggalan kata pada akhir kalimat dan spasi.

k. Kata "dan" dan "karena" tidak boleh di awal kalimat.

I. Mengutip pernyataan ilmuwan harus didasari referensi.

m. Keterangan gambar sebaiknya diletakkan di bawah gambar.

n. Pada latihan soal halaman 17 no 3, 5, dan 7 bahasa kalimatnya divariasi.

o. Soal evaluasi halaman 48 no 9 kurang lengkap.

p. Ukuran font pada rumus "Ketetapan Planck", "Jumlah Elektron", dan "Daftar Pustaka" terlalu besar.

q. Daftar isi diberi titik-titik untuk menujukkan halaman.

Saran dari dosen ahli integrasi keimanan sebagai berikut: a. Pengutipan ayat Alquran pada halaman 3 sebaiknya surat AlZalzalah ayat 7 dan 8 .

b. Pada fitur beradab tidak jelas. Harusnya diberikan penugasan terlebih dahulu lalu disisipkan fitur beradab atau diberikan kalimat yang sesuai materi lalu dikaitkan dengan adab yang sesuai.

c. Dimensi spiritual yang ada disesuaikan dimensi spiritual Kurikulum 2013.

d. Pada halaman 37, pengutipan ayat Alquran dicek ulang terjemahannya.

Ketiga saran dari dosen ahli di atas digunakan untuk merevisi produk. Revisian produk disebut draf II kemudian dinilai kelayakan menggunakan indikator dari BSNP. Hasil nilai kelayakan dosen ahli adalah $79 \%$. Hasil penilaian kelayakan draf II digunakan untuk merevisi yang masih kurang. Revisian draf II disebut draf III

\section{Ujicoba Produk}

Tahap ini mengujikan produk yang telah direvisi atas saran dosen ahli ke guru kemudian diujicobakan ke siswa di MAN 1 Surakarta, MA AI Islam Jamsaren, dan SMA-IT Nur Hidayah. Hasil penilaian kelayakan dari guru tersaji pada Tabel 2 dan penilaian kelayakan dari siswa tersaji pada Tabel 3.

Tabel 2. Penilaian Kelayakan dari Guru

\begin{tabular}{clc}
\hline Responden & Kelayakan & Presentase(\%) \\
\hline Guru & Isi & 79,16 \\
SMA IT Nur & Bahasa & 75,00 \\
Hidayah & Penyajian & 81,25 \\
& Desain & 54,16 \\
& Keimanan & 81,25 \\
\hline Guru & Isi & 62,50 \\
MAN 1 & Bahasa & 75,00 \\
Surakarta & Penyajian & 68,75 \\
& Desain & 62,50 \\
& Keimanan & 87,50 \\
\hline Guru & Isi & 83,33 \\
MA Al Islam & Bahasa & 79,16 \\
Jamsaren & Penyajian & 75,00 \\
& Desain & 83,33 \\
& Keimanan & 90,62 \\
\hline
\end{tabular}


Tabel 3. Penilaian Kelayakan dari Siswa

\begin{tabular}{clc}
\hline Responden & Kelayakan & Presentase(\%) \\
\hline Siswa & Isi & 83,88 \\
SMA IT Nur & Bahasa & 75,55 \\
Hidayah & Penyajian & 82,90 \\
& Desain & 73,33 \\
& Keimanan & 87,50 \\
\hline Siswa & Isi & 78,33 \\
MAN 1 & Bahasa & 75,27 \\
Surakarta & Penyajian & 80,41 \\
& Desain & 80,27 \\
& Keimanan & 86,25 \\
\hline Siswa & Isi & 72,77 \\
MA Al Islam & Bahasa & 75,00 \\
Jamsaren & Penyajian & 78,33 \\
& Desain & 64,16 \\
& Keimanan & 82,28 \\
\hline
\end{tabular}

Hal ini dikarenakan guru yang lebih memahami kemampuan pemahaman dan daya literasi siswa. Sehingga uji kelayakan ini sangat esensial bagi pengembangan produk buku ajar berbasis kimia. Hasil yang diperoleh dari uji kelayakan draf III positif, artinya secara keseluruhan aspek draf III selanjutnya layak untuk diuji kelayakannya oleh siswa, akan tetapi masih terdapat kekurangan dalam bagian desain. Nilai yang diberikan oleh guru, dua dari tiga sekolah tersebut desain draf III harus direvisi. Hal ini disebabkan karena draf III ilustrasi latar belakang yang ada di draf II dihilangkan, sehingga terdapat kesan kurang menarik untuk dibaca oleh siswa. Secara aspek isi, bahasa, penyajian, dan keimanan draf III telah layak, namun karena penilaian desain kurang bagus perlu dilakukan revisi terkait dengan tata letak ilustrasi latar belakang yang belum ada diganti yang menarik dibaca dan dipelajari oleh siswa. Hasil saran dan penilaian dari guru dijadikan acuan merevisi draf III. Revisian draf III disebut draf IV dan diujikan ke siswa.

Uji kelayakan oleh siswa merupakan uji kelayakan tahap akhir dan menentukan layak tidaknya buku ajar kimia berbasis keimanan yang dikembangkan. Draf buku ajar kimia berbasis keimanan yang digunakan dalam uji kelayakan ini adalah draf IV hasil revisi draf III yang telah diberikan penilaian dan masukkan oleh guru.

Hasil penilaian kelayakan dari siswa dapat disimpulkan bahwa, buku ajar kimia berbasis keimanan (draf IV) yang dikembangkan dari aspek isi menunjukkan siswa merasa mudah dan tertarik dalam mempelajari isi dalam buku ajar tersebut. Jika dilihat pada data, maka dapat disimpulkan bahwa isi dalam materi buku ajar ini kemudahan dalam memahami buku ajar kimia berbasis keimanan tergantung kategori prestasi sekolah. Hal ini disebabkan oleh materi yang dituliskan dalam buku ajar ini kurang familiar di kalangan siswa.

Dari aspek bahasa rata-rata siswa mampu memahami dengan jelas maksud dari bacaan yang dituliskan dalam buku ajar tersebut. Karena bahasa yang digunakan untuk menyajikan materi berdasarkan tingkat perkembangan berfikir, sosial-emosional, dan daya literasi siswa. Hal ini akan berpengaruh pada kemudahan menelaah materi.

Untuk aspek penyajian keruntutan dan kesesuaian ilustrasi dengan materi menurut perspektif siswa bagus. Materi yang runtut ibarat pisau bermata dua. Satu sisi mampu menyajikan materi yang komprehensif satu sisi lainnya dapat membuat jenuh. Dari data siswa dengan kategori tinggi dan sedang lebih menyukai materi yang runtut daripada siswa kategori rendah. Kesesuaian ilustrasi dengan materi mampu membantu memvisualisasikan materi. Hal tersebut membawa dampak positif dalam memahami materi.

Sedangkan dari aspek desain, desain buku ini lebih disukai oleh siswa di sekolah kategori sedang dan kurang disukai oleh siswa sekolah kategori rendah. Hal ini dikarenakan penilaian terhadap suatu desain bersifat subjektif. Akibatnya penilaian terhadap desain dalam buku ajar kimia berbasis keimanan memiliki perspektif yang berbeda-beda.

Secara keseluruhan, buku ajar kimia berbasis keimanan ini telah layak dijadikan buku ajar atau lebih tepatnya buku pengayaan bagi siswa. Akan tetapi perlu diperbaiki dalam pada aspek desain yang mampu menarik minat siswa. 


\section{KESIMPULAN}

Buku ajar berbasis keimanan telah dikembangkan dalam penelitian ini dilakukan melalui tahap menurut Borg dan Gall dengan sedikit modifikasi pada tahap uji kelayakan produk. Nilai keimanan yang menjadi poin penting dalam pengembangan buku ajar ini diadaptasi dari indikator nilai keimanan yang diusulkan oleh Zarman. Nilai keimanan yang diimplementasikan dalam buku ajar ini adalah (1) menyebutkan asma Allah ke dalam kalimat yang dianggap tidak mengakui eksistensi-Nya dalam penciptaan atau pengaturan objek di materi kimia, (2) menghubungkan temuan ilmiah dalam kimia dengan ayat Alquran dan Hadis yang terkait, (3) mencantumkan amalan yang terkait dengan materi setelah mempelajarinya, (4) mencantumkan ilmuwan Muslim yang berpengaruh di bidang kimia, dan (5) mencantumkan adab-adab dalam menuntut ilmu kimia. Indikator nilai keimanan tersebut dimplementasikan dalam bodytext maupun fitur buku.

Hasil uji kelayakan buku ajar berbasis keimanan menunjukkan bahwa buku ajar tersebut layak digunakan dalam proses pembelajaran di MA maupun SMA-IT dengan predikat bagus.

\section{UCAPAN TERIMA KASIH}

Saya mengucapkan syukur kepada Allah SWT, terima kasih kepada dosen pembimbing skripsi, warga sekolah MAN 1 Surakarta, MA Al Islam Jamsaren, dan SMA-IT Nur Hidayah, serta dosen UNIKOM Bandung yang memberikan inspirasi dan izin penelitian untuk menyelesaikan artikel ini.

\section{DAFTAR RUJUKAN}

[1] Devetak, I., and Vogrinc, J., "The Criteria for Evaluating the Quality of the Science Textbooks" in Critical Analysis of Science Textbooks. Eds. Khine, M.S., Springer, Dordrecht, 2013, 3-13.
[2] Martínez-Gracia, M. V., Gil-Quílez, M. J., \& Osada, J., Analysis of Molecular Genetics Content in Spanish Secondary School Text-books, 2006, Jurnal of Biological Education, 35-60.

[3] White, R.T., 1988, Learning Science, Oxford, Basil Blackwell.

[4] Altbach, P.G., 1987, "Textbook in Comparative Context" in Comparative and International Education Series: Educational Technology-lts Creation, Development, end Cross Cultural Transfer. Ed. Murray, T.R., and Kobayashi, V.N., Pergamon Press.

[5] Brown, T.L., Le May Jr, H.E., and Bursten, B.E., 1997, Chemistry the Central Science, New Jersey, Prentice Hall Internasional Inc.

[6] Chang, R., and Overby, J., 2003, General Chemistry: The Essential Consepts, New York, McGraw-Hill.

[7] Al-Attas, S.M.N., 1995, Islam dan Filsafat Sains, Bandung, Mizan.

[8] Zarkasyi, H.F., "Islamic Worldview sebagai Paradigma Sains Islam" in Islamic Science : Paradigma, Fakta, dan Agenda. Eds. Arif, S., Jakarta, Insist, 2016, 1-25.

[9] Borg, W.R., and Gall, M.G., 1983, Educational Research: An Introduction $\left(5^{\text {th }}\right.$ ed), New York, Longman

[10] Zarman, W., 2012, Studi Pengembangan Buku Teks Ilmu Pengetahuan Alam Sekolah Menengah Pertama Berbasis Nilai Keimanan, Disertasi, Bogor, Program Pascasarsajana Universitas Ibn Khaldun.

[11] Viana, H.E.B., and Porto, P.A., "The development of Dalton's atomic theory as a case study in the history of science: Reflections for educators in chemistry," Sci. Educ., vol. 19, no. 1, 75-90, 2010 